\title{
Maize meal slurry mixing: an economical recipe for precise aflatoxin quantitation
}

\author{
J. Kumphanda ${ }^{1,5}$, L. Matumba ${ }^{2 *}$, T.B. Whitaker ${ }^{3}$, W. Kasapila ${ }^{1}$ and J. Sandahl ${ }^{4}$ \\ ${ }^{1}$ Lilongwe University of Agriculture and Natural Resources, Bunda College Campus, Department of Food Science and \\ Technology, P.O. Box 219, Lilongwe, Malawi; ${ }^{2}$ Food Technology and Nutrition Group, Lilongwe University of Agriculture \\ and Natural Resources (LUANAR)-NRC campus, P.O. Box 143, Lilongwe, Malawi; ${ }^{3}$ Biological and Agricultural Engineering \\ Department, North Carolina State University, Weaver Laboratories, P.O. Box 7625, Raleigh, NC 27695-7625, USA; ${ }^{4}$ Science \\ E Technology Capacity Building Branch, Foreign Agricultural Service, Washington, DC 20250, USA; ${ }^{5}$ Malawi University \\ of Science and Technology, P.O. Box 5196, Limbe, Blantyre, Malawi; alimbikani@gmail.com
}

Received: 26 November 2018 / Accepted: 19 February 2019

(c) 2019 Wageningen Academic Publishers

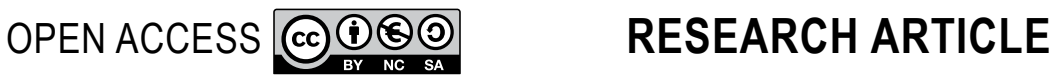

\begin{abstract}
The laboratory sample preparation for mycotoxin determination in cereals, often overlooked among sampling plans and analytical methods, was further studied. The precision of aflatoxin analysis in comminuted maize samples using $25 \mathrm{~g}$ slurry (prepared from $250 \mathrm{~g}$ test portion of comminuted maize, water/matrix $(1+1, \mathrm{v} / \mathrm{w}))$ and $12.5 \mathrm{~g}$ dry grind test portion were compared against the conventional $50 \mathrm{~g}$ dry grind test portion through replicated (10) Aflatest ${ }^{\circ}$ immunoaffinity fluorometric tests of naturally contaminated samples with aflatoxin concentration ranging from 4.9 to $81.7 \mu \mathrm{g} / \mathrm{kg}$. The overall mean aflatoxin concentration obtained from the 10 different samples tested using $12.5 \mathrm{~g}$ and $50.0 \mathrm{~g}$ dry grind procedures was $12 \%$ significantly $(P<0.05)$ lower (poorer) compared to $25 \mathrm{~g}$ slurry. The sample preparation plus analytical variance associated with testing $25.0 \mathrm{~g}$ slurry, $50.0 \mathrm{~g}$ dry grind and $12.5 \mathrm{~g}$ dry grind test portions were in the ratio of 1:5:15, respectively.
\end{abstract}

Keywords: dry grind, slurry mixing, sample preparation, aflatoxin analysis, maize, precision, recovery

\section{Introduction}

Aflatoxin contamination in grains, particularly maize, remains a major challenge globally (Battilani et al., 2016). Aflatoxins are toxic metabolites produced by a variety of Aspergillus species, notably Aspergillus flavus and Aspergillus parasiticus and are capable of causing cancer, mutagenesis, teratogenesis immunosuppression and nutrition interference in animal species and humans (Williams et al., 2004). Consequently, about 100 countries have established strict regulatory limits for aflatoxin in food to as low as $100 \mathrm{ng} / \mathrm{kg}$ in baby food to reduce dietary intake (EC, 2010; FAO, 2003).

These control activities require measurement methods that can accurately and precisely measure the true aflatoxin concentration in food and feed stuff. Typically, aflatoxin test procedure in grains consists of 3 steps: (1) the sampling step, where a random sample (laboratory sample) is taken from the lot; (2) the sample preparation step, where an entire laboratory sample is comminuted in a mill or grinder and a subsample (called a test portion) is drawn from the comminuted laboratory sample. Grinding and subsampling are collectively called the sample preparation step; (3) the analytical step, where aflatoxin in the test portion is solvent extracted, purified, and quantitated (Whitaker et al., 2010). Mostly, aflatoxin quantitation involves chromatographic technique such as thin-layer chromatography (TLC), gas chromatography (GC), or high-performance liquid chromatography (HPLC) coupled with a photo diode array, UV-Vis or fluorescent detector, or liquid chromatography with mass spectrometry (LC-MS) or tandem mass spectrometry (LC-MS/MS) (Berthiller et al., 2017; Shephard, 2016). However, recently fluorometer based detection of aflatoxin has become popular (Magamba et al., 2017; Manoza et al. 2017; Nishimwe et al., 2017; Schwartzbord and Brown, 2015).

The variability associated with each of the 3 steps contributes to the total variability (random errors) 
associated with the aflatoxin test procedure. However, studies on a wide variety of agricultural products indicate that the sampling step is generally the largest source of variability followed by sample preparation and analysis in that decreasing order (Johansson et al., 2000a; Ozer et al., 2017; Whitaker, 2006; Whitaker et al., 1974). Although it is impossible to completely eliminate sampling variability, several workers have developed sampling plans that reduce random error to levels considered to be acceptable by those responsible for interpreting and reporting the surveillance data (Johansson et al., 2000a; Whitaker, 2003). Similarly, many analytical methods have been validated and used for the analysis of aflatoxins (Berthiller et al., 2017; Shephard, 2016; Turner et al., 2015).

While great efforts have been made to establish reliable sampling plans and analytical methods with acceptable performance criteria, little attention has been paid to the sample preparation phase. Typically, during sample preparation, a laboratory sample of several kilograms is dry ground and the comminuted sample is thoroughly mixed to try and approach complete homogenisation. A small subsample, called a test portion, is removed from the comminuted sample for extraction of the mycotoxin to minimise costs associated with extraction solvents. However, for a given particle size distribution, test portion size has an effect on the variance associated with the sample preparation step. Whitaker et al. (1994) found that halving a size of test portion increased variance by a factor of 2. For example, variance associated with a $10 \mathrm{~g}$ dry grind test portion from a Romer mill was found to be five times greater than the variance associated with a 50 $\mathrm{g}$ dry grind test potion (Whitaker, 2006). From a series of studies, Whitaker and his group, concluded that analysing a $50 \mathrm{~g}$ test portion (dry grind) taken from a laboratory sample comminuted in a Romer mill is the minimum that should be employed with reasonably acceptable variance. Consequently, analysis of 25 to $50 \mathrm{~g}$ dry grind test portion were typical test portion sizes recommended for extraction when the laboratory sample is dry-ground in commercially available mills, such as the Romer mill (Bansal et al., 2011; Firdous et al., 2014; Garrido et al., 2012; Lewis et al., 2005). However, the cost associated with analysis of the larger test portion sizes ( 25 to $50 \mathrm{~g}$ dry grind test portions) is still considered to be high particularly in resource constrained settings including Africa where extraction solvents are mostly imported from overseas.

Studies on several agricultural products, mostly oil seeds have shown that slurry-mixing approaches can potentially reduce sample preparation variance (Schatzki and Toyofuku, 2003; Spanjer et al., 2006; Velasco and Morris, 1976; Whitaker et al., 1980, 1994). However, it is not very clear if such reduction in variance could be leveraged to successfully reduce test portion size further from the $50 \mathrm{~g}$. Therefore, this study was performed to explore the most economical (minimum) test portion mass of a maize slurry that could practically be used in the analysis of aflatoxin using VICAM Aflatest $^{\ominus}$ (Vicam, Milford, MA, USA) immunoaffinity fluorometric analysis without compromising precision with reference to analysis of conventional $50 \mathrm{~g}$ dry grind test portion. Drawing from the above, we derived the following hypothesis: 'better precision of aflatoxin quantification in maize meal is achievable by slurry mixing a large test portion and analysing a small fraction of it than using the conventional $50 \mathrm{~g}$ dry grind'. Further, the variance associated with $25 \mathrm{~g}$ slurry ( $12.5 \mathrm{~g}$ maize), $12.5 \mathrm{~g}$ dry grind and the conventional $50 \mathrm{~g}$ dry grind procedures and the effect of matrix/water ratio in a slurry on the recovery and precision were studied and discussed.

\section{Materials and methods}

\section{Maize sample and preparation}

Ten naturally contaminated maize samples ( $2 \mathrm{~kg}$ each) varying in aflatoxin concentration were bought from Chapananga market in Chikwawa district (Malawi) and separately ground to pass sieve \# 20 (opening size $=0.85$ $\mathrm{mm}$ ) using Romer Labs Series II ${ }^{\odot}$ mill (Romer Labs, Inc., Union, MO, USA). The choice of Romer mill was based on the fact that it is the most frequently used mill for quality control in mycotoxin analysis, providing both grinding and subsampling of grains (Lippolis et al., 2012; Nowicki and Roscoe, 2010; Spanjer et al., 2006; Whitaker et al., 2000). Two kilograms ( $2 \mathrm{~kg}$ ) of each comminuted sample was then apportioned into $1 \mathrm{~kg}, 500 \mathrm{~g}$ and two $250 \mathrm{~g}$ sub-samples using a riffle-divider (Humboldt Testing Equipment, Norridge, IL, USA).

\section{Study design}

Four experiments were performed to achieve the study objective. The first experiment was performed to determine the minimum test portion mass of a slurry that could practically be employed to analyse aflatoxin in a maize sample based on an equivalent Aflatest VICAM dry grindbased extraction procedure. In this procedure, a $10 \mathrm{ml}$ volume filtered extract is required for the analysis.

Five different slurry aliquots of 30, 25, 20, 15 and $10 \mathrm{~g}$ prepared by mixing water/matrix $(1+1, \mathrm{v} / \mathrm{w})$ ratio were tried. The water matrix ratio of $1+1$ was used to match the Aflatest VICAM dry grind-based extraction procedure. After blending the maize/water mixture for $3 \mathrm{~min}$, the slurry was blended at high speed for 2 min following the addition of an appropriate volume of methanol aimed at achieving a mixture of water/matrix/methanol $(1+1+3, \mathrm{v} / \mathrm{w} / \mathrm{v})$ ratio. Finally, the volume of filtrate (passed through fluted paper) obtained at the end of $2 \mathrm{~min}$ was recorded. 
Informed by results of the first experiment, the second experiment was performed to compare the combined sample preparation plus analytical variance $\left(\mathrm{s}^{2}{ }_{\mathrm{spa}}\right)$ associated with aflatoxin analysis of $12.5 \mathrm{~g}$ dry grind, $50 \mathrm{~g}$ dry grind and 25 g slurry [water/matrix $(1+1, \mathrm{v} / \mathrm{w})]$ test portions taken from naturally contaminated maize samples (Figure 1 ). The combined sample preparation plus analytical variance is the sum of the sample preparation variance $\left(\mathrm{s}^{2}{ }_{\mathrm{sp}}\right)$ plus the analytical variance $\left(\mathrm{s}^{2}{ }_{\mathrm{a}}\right)$.

$\mathrm{s}^{2}{ }_{\mathrm{spa}}=\mathrm{s}_{\mathrm{sp}+}^{2} \mathrm{~s}_{\mathrm{a}}^{2}$

The maize slurry was prepared by mixing $250 \mathrm{~g}$ of the ground maize with $250 \mathrm{ml}$ distilled water (water/matrix ratio of $1+1, \mathrm{v} / \mathrm{w}$ ) and blended at high speed for $3 \mathrm{~min}$. It is important to note that the $12.5 \mathrm{~g}$ dry grind and $25 \mathrm{~g}$ slurry only differ in one respect, the sequence in which the extraction fluid is added. In dry grind treatment, the steps are (1) weigh $12.5 \mathrm{~g}$ test portion, (2) add $1.25 \mathrm{~g}$ of $\mathrm{NaCl}$, (3) add $50 \mathrm{ml}$ of blend of $12.5 \mathrm{ml}$ of water and $37.5 \mathrm{ml}$ of $\mathrm{MeOH}$, (4) blend for $2 \mathrm{~min}$ in a blender, and (5) filter. For the slurry treatment, the sequence is (1) weigh $250 \mathrm{~g}$ test portion of dry ground maize and add $250 \mathrm{ml}$ water, (2) blend for 3 min to make slurry, (3) weigh out $25 \mathrm{~g}$ of slurry, (4) add $1.25 \mathrm{~g} \mathrm{NaCl}$, (5) add $37.5 \mathrm{ml} \mathrm{MeOH,} \mathrm{(6)} \mathrm{blend} \mathrm{for}$ 2 min, and (7) filter.

For each of the 10 samples, 10 replicates (Figure 1) from each of the three test portion treatments were measured

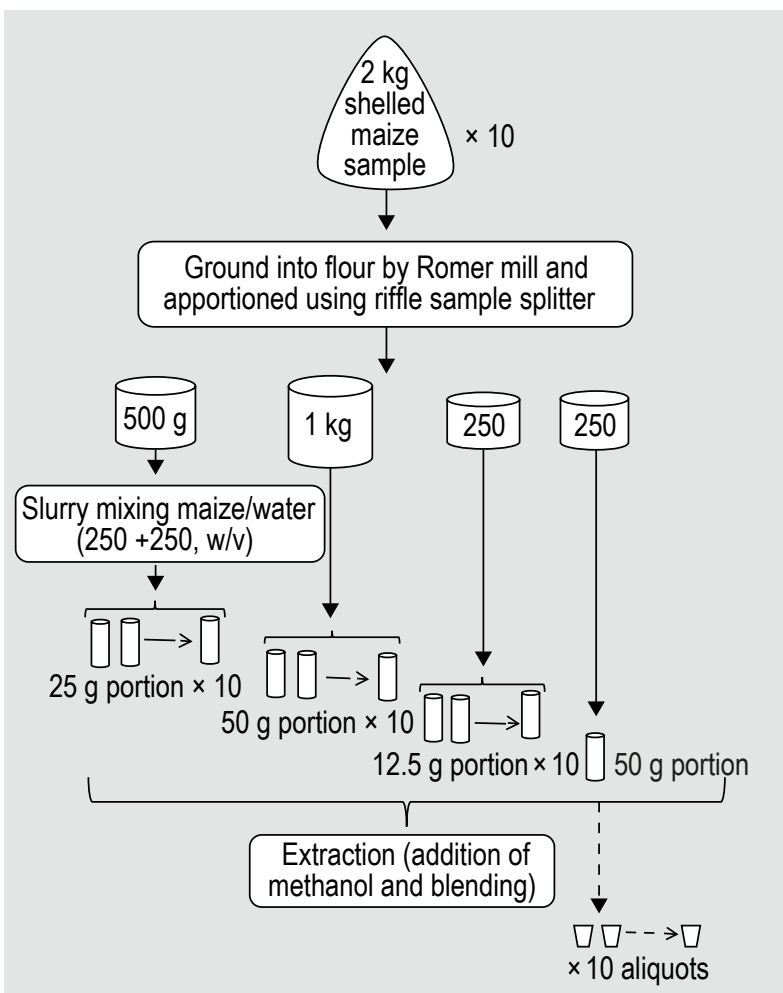

Figure 1. Scheme of sample preparation (second experiment). for aflatoxin to elucidate the combined sample preparation plus analytical variance $\left(\mathrm{s}^{2}{ }_{\text {spa }}\right)$. Additionally, for each of the 10 samples, 10 aliquots from a single $50 \mathrm{~g}$ dry grind sample extract were analysed to elucidate the analytical variance $\left(\mathrm{s}^{2}{ }_{\mathrm{a}}\right)$ associated with the Aflatest immunoaffinity fluorometric analytical procedure (Figure 1). It is assumed that the analytical variance is the same for all three test portion treatments.

The third experiment was performed to determine the effect of duration of blending on extraction efficiency. In this regard, the efficacy of extracting aflatoxin from a $50 \mathrm{~g}$ dry grind test portion (in triplicate) for 2- and 5-min blend times were compared. In this experiment, the 2-min blending represents the common practice as outlined in the VICAM Aflatoxin Test Manual (VICAM, 2014). On the other hand, the 5-min blending represents the sum of blending times involved in slurry preparation $(3 \mathrm{~min}$ ) and the conventional methanol/water extraction $(2 \mathrm{~min})$.

The fourth experiment was performed to determine the effect of water/matrix ratio on the precision of scooping maize solids during weighing of test portions. In this regard, three water/matrix ratios of $2 / 5,1 / 1$ and $8 / 5$ were evaluated based on common practice and insights from previous experiments (Cole and Dorner, 1994; Stroka, 2000). The slurries were prepared by blending the water/matrix mixtures for $3 \mathrm{~min}$ as described earlier. Subsequently, $25 \mathrm{~g}$ test portions ( 6 replicates) were scooped into pre-weighed dishes using spatula and dried in an oven at $120{ }^{\circ} \mathrm{C}$ for $4 \mathrm{~h}$. The mass of the dried test portion was recorded after cooling the aliquot in a desiccator and the percent error was calculated as a measurement of the discrepancy between an observed (experimental) mass and expected mass using the following formula:

(observed mass - expected mass) $\times 100$

Percent error $=\frac{\text { expected mass }}{}$

Where the expected mass refers to anticipated theoretical mass of solids based on the water-solid combination in a slurry adjusted for $10 \%$ intrinsic moisture loss incurred during drying assay.

\section{Aflatoxin determination}

Extraction and clean-up of aflatoxin from maize test portions was performed using a modified version of the manufacturer's instruction for the Aflatest immuno-affinity procedures for popcorn (VICAM, 2014). Aflatoxin was extracted from the dry-ground test portions (50 g maize + $5 \mathrm{~g} \mathrm{NaCl}$ and $12.5 \mathrm{~g}$ maize $+1.25 \mathrm{~g} \mathrm{NaCl}$ ) with $200 \mathrm{ml}$ and $50 \mathrm{ml}$ of methanol/water $(150+50 \mathrm{v} / \mathrm{v})$ and $(37.5+12.5 \mathrm{v} / \mathrm{v})$, respectively, and blended at high speed for $2 \mathrm{~min}$. Similarly, extraction of aflatoxin from $25 \mathrm{~g}$ slurry-mixing portions involved $37.5 \mathrm{ml} \mathrm{HPLC}$ grade methanol blend at high speed 
for $2 \mathrm{~min}$. The triturated mixture was filtered through fluted paper to remove particulate matter. A $10 \mathrm{ml}$ volume of the filtered extract was diluted with $40 \mathrm{ml}$ distilled water, mixed and filtered through a glass-fibre filter paper. A $20 \mathrm{ml}$ (1 g sample equivalent) of the diluted extract was passed through Aflatest immuno-affinity column at a flow rate of about 1-2 drops/s. The column was washed twice with $(10 \mathrm{ml})$ distilled water at a rate of ( 2 drops/s) to remove maize intrinsic compounds and finally the aflatoxins were selectively eluted with $1 \mathrm{ml}$ of $100 \%$ HPLC grade methanol into a glass cuvette. One $\mathrm{ml}$ of Aflatest developer (developer/ water of $9+1, \mathrm{v} / \mathrm{v}$ ) was added to elute in the cuvette and mixed using vortex before reading the sample in a calibrated VICAM Series-4EX Fluorometer.

\section{Recovery experiments}

Reference maize sample (R-Biopharm AG, Darmstadt, Germany) at certified concentration for aflatoxin = $24.4 \mu \mathrm{g} / \mathrm{kg}$ was analysed using $12.5 \mathrm{~g}$ dry grind, $50 \mathrm{~g}$ dry grind and 25 g slurry (12.5 g maize) approaches to determine recoveries and relative standard deviation (RSD) corresponding to recovery values. Analysis of the reference material was done in four replicates except for the $50 \mathrm{~g}$ dry grind which had three replicates. Further, repeatability (RSDr) (the repeatability CV) was evaluated by performing the assay on five replicates of naturally contaminated maize meal and performed by the single operator on the same day (intra-day precision) and during five consecutive days (interday precision). The results were expressed as the percentage of relative standard deviation of the measurements (\%RSD).

\section{Statistical analysis}

Microsoft Excel (Microsoft Corporation, Redmond, WA, USA) and SPSS version 23 (IBM Corp, Armonk, NY, USA) were used for statistical analysis and data presentation. The differences among using $25 \mathrm{~g}$ slurry to $12.5 \mathrm{~g}$ and $50 \mathrm{~g}$ dry grind procedures were analysed by one-way ANOVA. Results showing significant differences were subjected to post-hoc Tukey's test with significance for $P<0.05$.

\section{Results}

\section{Filtrate volumes attainable from $30,25,20,15$, and $10 \mathrm{~g}$ of} maize slurry

The filtrate volumes obtained from five different test portion sizes are presented in Supplementary Figure S1. As expected, the filtrate volumes decreased with a reduction in test portion (Filtrate $=0.602 \times$ mass of slurry $-1.7 ; \mathrm{R}^{2}=$ 0.9824). Of the experimented test portions, the $25 \mathrm{~g}$ of slurry was found to be the minimum mass that constantly yielded sufficient volume (enough to practically pipette $10 \mathrm{ml}$ ) required for the Aflatest immunoaffinity fluorometric assay within 2 min filtration time. Consequently, the $25 \mathrm{~g}$ slurry test portion (12.5 g water $+12.5 \mathrm{~g}$ maize) was used in subsequent experiments.

\section{The effect of extraction blending time on aflatoxin recovery}

The effect of extraction time on aflatoxin recovery was examined by comparing 2- and 5-min blending time with constant experimental conditions. Blending $50 \mathrm{~g}$ maize meal (in triplicate) with $200 \mathrm{ml}$ methanol/water $(150+50 \mathrm{v} / \mathrm{v})$ for 2 and 5 min yielded $8.1 \pm 1.7$ and $7.8 \pm 1.3 \mu \mathrm{g} / \mathrm{kg}$, respectively, with no significant $(P<0.05)$ difference according to t-test.

\section{Effect of water/maize ratio on the precision of scooping maize proportion (dry solids)}

Results on effect of water/matrix (maize) ratio on the precision of scooping maize proportion (dry solids) during weighing of test portions are presented in Supplementary Table S1. Water/maize ratio had no effect on the precision of scooping maize proportion (dry solids) over the studied range $(2 / 5-8 / 5)$. The percent errors associated with all the three water/matrix ratios $(2 / 5,1 / 1$ and $8 / 5)$ were less than $3 \%$.

\section{Variability of aflatoxin results obtained with $12.5 \mathrm{~g}$ dry grind, $50 \mathrm{~g}$ dry grind and $25 \mathrm{~g}$ slurry preparation procedures}

Aflatoxin analysis (10 replications) of $12.5 \mathrm{~g}$ dry grind, $50 \mathrm{~g}$ dry grind and $25 \mathrm{~g}$ slurry [water/matrix $(1+1, \mathrm{v} / \mathrm{w})$ ] of ten different naturally contaminated maize samples is presented in Supplementary Table S2, with total aflatoxin concentrations ranging from 4.9 to $81.7 \mu \mathrm{g} / \mathrm{kg}$. The combined sample preparation plus analytical variance (analytical variance reflects the VICAM Aflatest immunoaffinity fluorometric analysis) associated with aflatoxin testing using $12.5 \mathrm{~g}$ dry grind, $50 \mathrm{~g}$ dry grind and the 25 g slurry sample preparation procedures are displayed in Figure 2. Assuming a power function is appropriate (Johansson et al., 2000b; Whitaker et al., 1974), a regression analysis was run on the combined sample preparation plus analytical variance $\left(\mathrm{s}_{\text {spa }}^{2}\right)$ versus aflatoxin concentration (C) for each sample preparation procedure.

12.5 g dry grind: $\mathrm{s}^{2}$ spa $=0.9005 \mathrm{C}^{1.3625}$

50 g dry grind: $\mathrm{s}^{2}{ }_{\mathrm{spa}}=0.135 \mathrm{C}^{1.595}$

25 g slurry: $\mathrm{s}_{\text {spa }}^{2}=0.0611 \mathrm{C}^{1.3268}$

The combined sample preparation plus analytical variance associated with $12.5 \mathrm{~g}$ dry grind sample preparation procedure ranged from 10.2 to $499.4 \mu \mathrm{g}^{2} / \mathrm{kg}^{2}$ (mean $160.1 \mu^{2} / \mathrm{kg}^{2}$ ) while as for the $50 \mathrm{~g}$ dry grind and $25 \mathrm{~g}$ slurry ranged from 2.6 to $134.4 \mathrm{\mu g}^{2} / \mathrm{kg}^{2}$ (mean $55.6 \mu \mathrm{g}^{2} / \mathrm{kg}^{2}$ ), 
and 0.7 to $32.1 \mu \mathrm{g}^{2} / \mathrm{kg}^{2}$ (mean $11.0 \mu \mathrm{gg}^{2} / \mathrm{kg}^{2}$ ), respectively (Figure 2; Supplementary Table S2). Therefore, the mean combined variance associated with testing $12.5 \mathrm{~g}$ dry grind, $50 \mathrm{~g}$ dry grind and $25 \mathrm{~g}$ slurry were in the ratio of 15:5:1, respectively. The variance was positively related with aflatoxin concentration. The functional relationship between combined variance associated with the three sample preparation approaches and aflatoxin concentration is described by equations that are shown in Figure 2. For all the three sample preparation approaches, the coefficient of determination for the regression equation was greater than 0.8 (Figure 2).

The analytical variances $\left(\mathrm{s}_{\mathrm{a}}^{2}\right)$ associated with the Aflatest immunoaffinity fluorometric method used in the present study are plotted against aflatoxin concentration in Figure 3. Similar to trends observed with combined variance, the analytical variance appeared to be a function of aflatoxin concentration. From a regression analysis the analytical variance is:

$\mathrm{s}^{2}{ }_{\mathrm{a}}=0.0473 \mathrm{C}^{1.2743}$

For aflatoxin concentration between 4.9 to $81.7 \mu \mathrm{g} / \mathrm{kg}$, the Aflatest immunoaffinity fluorometric analytical variance ranged from 0.3 to $8.8 \mu^{2} / \mathrm{kg}^{2}$ (mean $5 \mu \mathrm{g}^{2} / \mathrm{kg}^{2}$ ). The ratio of the analytical variance to combined variance was generally small particularly for $12.5 \mathrm{~g}$ dry grind and the $50 \mathrm{~g}$ dry grind approaches. The ratios of analytical variance to combined variance arising from aflatoxin testing of the 10 samples using $12.5 \mathrm{~g}$ dry grind and the $50 \mathrm{~g}$ dry grind approaches ranged from 1.0 to $5.8 \%$ (mean \pm standard deviation (SD), $3.9 \pm 1.5 \%$ ) and $4.6-39.6 \%$ (mean \pm SD, $12.9 \pm 9.7 \%$ ). Strikingly, the ratio of analytical variance to combined variance was comparatively higher in $25 \mathrm{~g}$ slurry ranging from 28.2 to $74.3 \%$ (mean \pm SD, $50.8 \pm 14.8$ ). In other words, the variance arising from slurry mixing of $250 \mathrm{~g}$ Romer Mill dry ground maize and analysing an aliquot of $25 \mathrm{~g}$ slurry [water/matrix $(1+1, \mathrm{v} / \mathrm{m})]$ was so low and comparable or even less than the analytical variability.

The variances associated with sample preparation $\left(\mathrm{s}^{2}{ }_{\mathrm{sp}}\right)$ for the three test portion treatments can be determined by solving for $\mathrm{s}_{\mathrm{sp}}^{2}$ in Equation 1.

$\mathrm{s}^{2}{ }_{\mathrm{sp}}=\mathrm{s}_{\mathrm{spa}}^{2}-\mathrm{s}^{2}{ }_{\mathrm{a}}$

Then $\mathrm{s}_{\mathrm{sp}}^{2}$ for the three sample prep procedures:

$12.5 \mathrm{~g}$ dry grind: $\mathrm{s}_{\mathrm{sp}}^{2}=0.9005 \mathrm{C}^{1.3625}-0.0473 \mathrm{C}^{1.2743}$

50 g dry grind: $\mathrm{s}_{\mathrm{sp}}^{2}=0.135 \mathrm{C}^{1.595}-0.0473 \mathrm{C}^{1.2743}$

25 g slurry: $\mathrm{s}_{\mathrm{sp}}^{2}=0.0611 \mathrm{C}^{1.3268}-0.0473 \mathrm{C}^{1.2743}$

The coefficients of variation $(\mathrm{CV})$ associated with aflatoxin test procedures involving $12.5 \mathrm{~g}, 50 \mathrm{~g}$ and $25 \mathrm{~g}$ slurry [water/

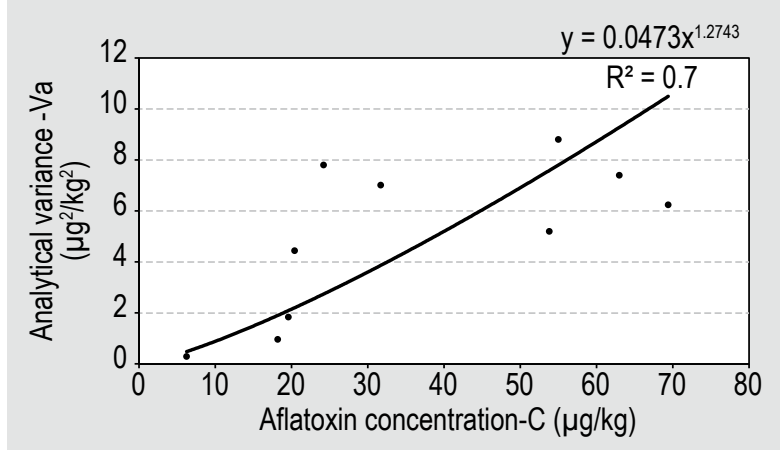

Figure 3. Analytical variance associated with VICAM Aflatest ${ }^{\circledR}$ immunoaffinity fluorometric method.

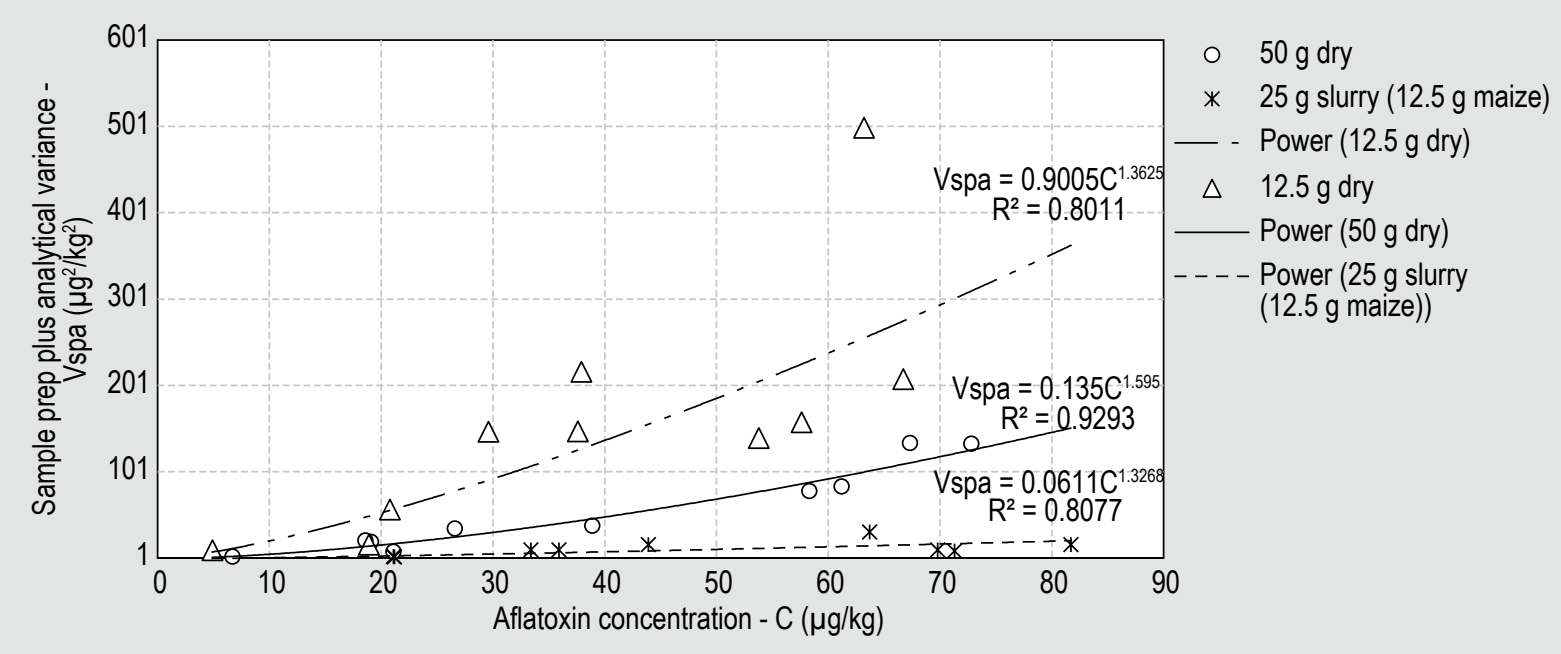

Figure 2. A plot of sample prep plus analytical variance against mean aflatoxin concentration showing difference in the variance among three sample preparation procedures. 
matrix $(1+1, \mathrm{v} / \mathrm{w})]$ of maize test portions comminuted in the Romer mill, and analysing one aliquot by the Aflatest immunoaffinity fluorometric method are shown over a range of aflatoxin concentrations in Figure 4. Each CV represents the combined variability associated with sample preparation plus analytical steps. The mean CV\% associated with the three different sample preparation approaches differed significantly $(P<0.05)$. The overall mean CV\% associated with $12.5 \mathrm{~g}$ dry grind, $50 \mathrm{~g}$ dry grind and the 25 g slurry were $33.6,18.7$ and $7.8 \%$, respectively, which translate to the ratio of $4: 2: 1$, respectively.

However, for all the three sample preparation procedures, as expected, the CV\% values improved (decreased) with increasing aflatoxin concentration (Figure 4). It is worth noting that linear relationship between $\mathrm{CVs}$ and aflatoxin concentration, $\mathrm{C}$, displayed in Figure 4 is also predictable from the variance equations $(\mathrm{CV}=\mathrm{S} / \mathrm{C})$ where $\mathrm{S}$ is the standard deviation or square root of variance.

$$
\begin{aligned}
& 12.5 \text { g dry grind: } C V_{\text {spa }}=0.949 C^{-0.3188} \\
& 50 \text { g dry grind: } C V_{\text {spa }}=0.3674 C^{-0.2015} \\
& 25 \text { g slurry: } C V_{\text {spa }}=0.2472 C^{-0.3366}
\end{aligned}
$$

Further results on intra-day and inter-day repeatability (precision) (RSDr) for $50 \mathrm{~g}$ dry grind and $25 \mathrm{~g}$ slurry approaches are provided in Table 1. Similar to the trends observed during analysis of the 10 different samples (aflatoxin concentration varied from 4.9 to $81.7 \mu \mathrm{g} / \mathrm{kg}$ ), the 25 g slurry procedure produced lower intra-day and inter-day RSDr values compared to $50 \mathrm{~g}$ dry grind approach.

\section{Effect of slurry mixing on aflatoxin extraction efficiency}

The overall mean aflatoxin concentration obtained from the 10 different samples tested using $12.5 \mathrm{~g}$ and $50 \mathrm{~g}$ dry grind procedures were found to $12 \%$ significantly $(P<0.05)$ lower (poorer) compared to the mean obtained by using 25 g slurry approach (Table 2). Likewise, lower extraction percentage/recovery (about 10\% lower) was observed with 12.5 and $50 \mathrm{~g}$ dry grind approaches as compared to the $25 \mathrm{~g}$ slurry procedure when reference material with $24.4 \mu \mathrm{g} / \mathrm{kg}$ aflatoxin concentration was analysed (Table 3). Lower aflatoxin recoveries for dry grind approaches are also seen in Table 1 displayed earlier.

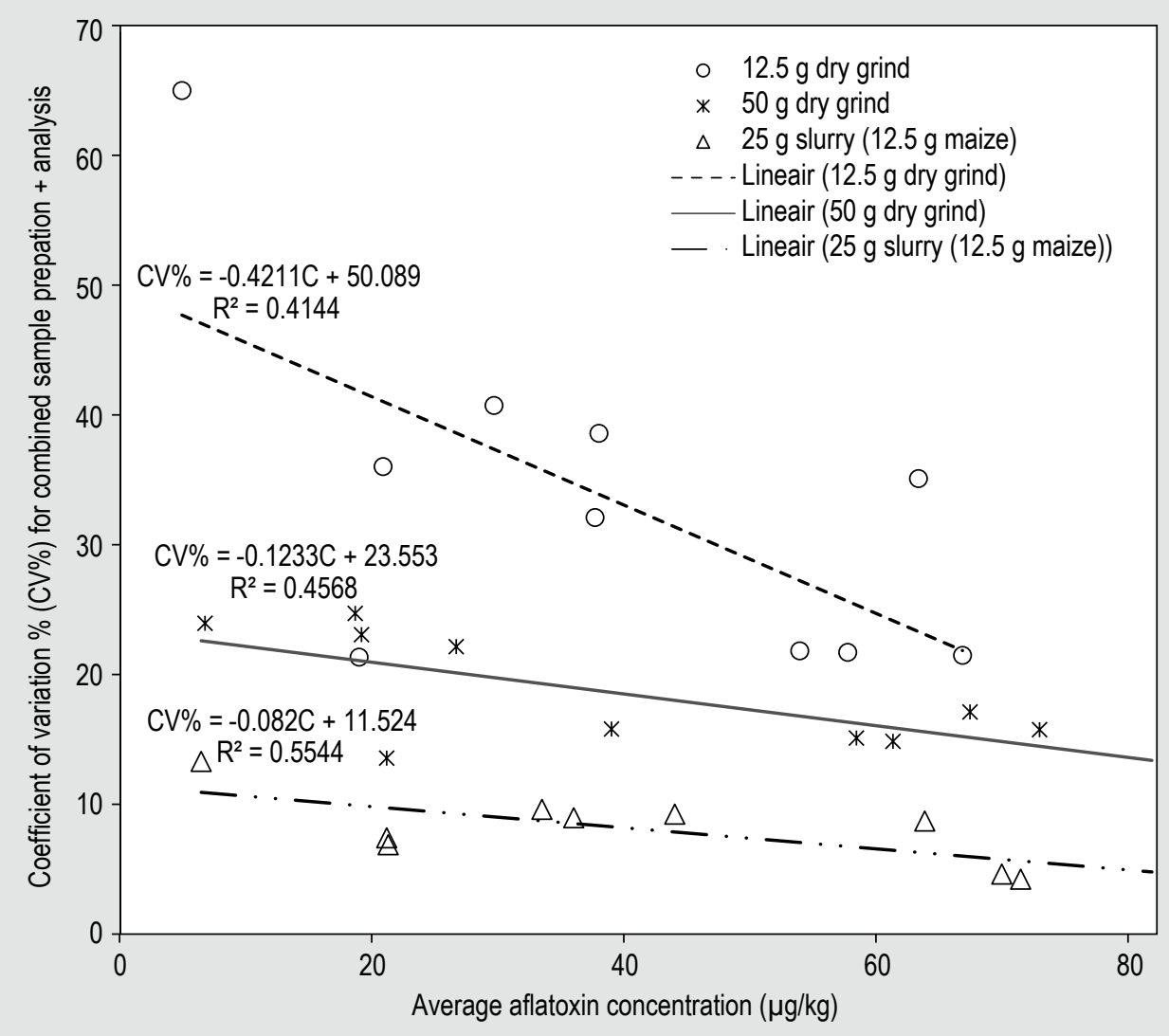

Figure 4. Relationship between aflatoxin concentration (C) and coefficient of variation (CV) \% for the $50 \mathrm{~g}$ dry grind, $12.5 \mathrm{~g}$ dry grind and $25 \mathrm{~g}$ slurry sample preparation procedures. 
Table 1. Intra-day and inter-day assay precision of aflatoxin results obtained with $\mathbf{5 0} \mathrm{g}$ dry grind and $25 \mathrm{~g}$ slurry obtained from same sample.

\begin{tabular}{|c|c|}
\hline \multirow[t]{2}{*}{ Sample preparation approach } & Intra-day precision ${ }^{1}$ \\
\hline & Aflatoxin $^{3}(\mu \mathrm{g} / \mathrm{kg})$ \\
\hline $50 \mathrm{~g}$ dry grind & $55.0 \pm 7.6$ \\
\hline 25 g slurry & $66.8 \pm 4.9$ \\
\hline \multicolumn{2}{|c|}{${ }^{1}$ Five replicates performed by same operator on same day. } \\
\hline \multicolumn{2}{|c|}{${ }^{2}$ Five replicates performed by same operator during five consecutive da } \\
\hline \multicolumn{2}{|c|}{${ }^{3}$ Results are mean \pm standard deviation. } \\
\hline
\end{tabular}

$\begin{array}{ll}\text { Procedure } & \text { Mean }^{1,2} \\ 12.5 \mathrm{~g} \text { dry grind } & 39.09^{\mathrm{a}} \\ 50.0 \mathrm{~g} \text { dry grind } & 39.06^{\mathrm{a}} \\ 25.0 \mathrm{~g} \text { slurry (12.5 g maize) } & 44.84^{\mathrm{b}}\end{array}$

${ }^{1}$ The overall mean represents averages of aflatoxin concentration from all ten samples analysed.

2 Values with a different superscript letter are significantly different $(P<0.05)$.

Table 3. Means, relative standard deviation (RSD) and extraction percentage for reference material ( $24.4 \mu \mathrm{g} / \mathrm{kg}$ aflatoxin) analysed using three different sample preparation procedures.

$\begin{array}{llll}\begin{array}{l}\text { Sample preparation } \\ \text { procedure }\end{array} & \text { Mean }(n=4) & \text { RSD \% } & \text { Extraction \% } \\ & & & \\ & & & \\ 12.5 \text { g dry grind } & 21.4 & 5.0 & 87.5 \\ 50.0 \text { g dry grind } & 21.7 & 4.7 & 88.9 \\ 25.0 \text { g slurry (12.5 g maize) } & 23.9 & 2.2 & 97.8\end{array}$

\section{Discussion}

Improvements in sampling and sample preparation methods used to determine mycotoxin content in food continues to be a high priority among regulatory agencies, international organisations and commodity industries worldwide (Berthiller et al., 2017). The present study has broadly explored the economical (minimum) test portion mass of a maize slurry in terms of methanol requirement that could practically be used to analyse aflatoxin without compromising recovery and precision with reference to analysis of conventional $50 \mathrm{~g}$ dry grind test portion. Furthermore, the efficiency of extraction of aflatoxin for the two approached have been compared. The results demonstrate supremacy of $25 \mathrm{~g}$ water slurry mixing procedure over the $50 \mathrm{~g}$ dry grind procedure as regard to recovery and precision. The current exploration focused on Aflatest immunoaffinity fluorometric assay, however, the findings have wide applications and could significantly contribute to improvement of accuracy of mycotoxin quantitation worldwide.

Unlike previous studies which either investigated the effect of test portion mass reduction (Whitaker, 2006; Whitaker et al., 1996) or slurry mixing (Spanjer et al., 2006; Velasco and Morris, 1976) on recovery and precision, the present study uniquely investigated both variables simultaneously thus enabling direct comparison of these effects particularly because 25 g slurry comprised $12.5 \mathrm{~g}$ dry maize mass. The variance ratio of 15:5:1 for $12.5 \mathrm{~g}$ dry grind: $50 \mathrm{~g}$ dry grind: 25 g slurry mixing observed in the present study clearly indicate that slurring $250 \mathrm{~g}$ and testing 25 g slurry mass (which represents $12.5 \mathrm{~g}$ maize meal) has a greater (factor of 15 derived from 15:1) effect on improving precision than increasing test portion mass from $12.5 \mathrm{~g}$ dry grind to $50 \mathrm{~g}$ dry grind (factor of 3 derived from 15:5). Conversely reducing mass of test portion from a conventional $50 \mathrm{~g}$ dry grind to $12.5 \mathrm{~g}$, increased variance by a factor of 3 which is closer to the value (4) predicted by Whitaker (2006) and Whitaker et al. (1996). A ratio less than 4 is expected since $\mathrm{s}^{2}$ spa for each of the three test portion treatments has an analytical variance (Equation 1) component in the ratio.

Paradoxically, recent years have witnessed a dramatic reduction in test portion mass selected from the dry grinding of a laboratory sample with most laboratories extracting mycotoxins from a test portion smaller than 10 g of dry grind (Matumba et al., 2017). In particular, studies that quantified mycotoxin in maize meal in European laboratories and published during 1997-2006 and 2007-2016 in Mycotoxin Research Journal had median test portion mass of $15 \mathrm{~g}$ and $5 \mathrm{~g}$, respectively. This trend is worrisome if one considers that CVs for a given fineness of grind increase 
with regard to lower levels of aflatoxin contamination. Thus, for lots where the aflatoxin concentration is close to the permissible/legal limit (often set at very low level, see FAO, 2003), consumers may be placed at risk of exposure to hazardous aflatoxin levels and processors placed at the risk of falsely rejecting an otherwise acceptable lot particularly when a conventional mill with sieve openings of $0.85 \mathrm{~mm}$ is used. When recommending small test portion sizes (i.e. $10 \mathrm{~g}$ ) for extraction, it is extremely important to make sure the particle size resulting from the comminution process is very small to compensate for the recommended small test portion size. This study demonstrated that using waterslurry methods provides an easy and low-cost approach to reducing maize particle size so that the smaller maize mass (12.5 g) can be used in the extraction process without increasing sample preparation variability.

The good precision of the $25 \mathrm{~g}$ slurry procedure witnessed in the present study is not surprising. Slurry mixing increases degree of sample comminution (reduces particle size) which in turn enhances homogeneity of the test sample portion (Whitaker and Johansson, 2005; Whitaker et al., 1980). However, there were concerns that the homogeneity could be influenced by water/matrix ratio as it could affect efficiency of distribution of particles (homogeneity) and slurry stability (suspended solids separating from slurry water over a prolonged time period). To the contrary, the results from the scooping experiment performed over the water/matrix ratio 2/5-8/5 (Supplementary Table S2), show high stability as evidenced by good precision of scooping maize proportion (dry solids). These results demonstrate the robustness of slurry mixing used in this study.

High extraction efficiency of slurry mixing procedure observed in the present corroborates earlier studies. Velasco and Morris (1976) and Whitaker et al. (1980) obtained 32 and $33 \%$ higher aflatoxin recoveries in groundnuts, respectively, with slurry mixing than when dry grinding was employed. Later, Schatzki and Toyofuku (2003) also noted higher $(32 \%)$ recoveries with slurry mixing approach. Several explanations are given for the higher aflatoxin extraction efficiencies. These include extraction time (slurring mixing $+\mathrm{MeOH}$ extraction) and possible swelling or an exchange of $\mathrm{H}$-bonding between aflatoxin and the matrix which eventually improves release of aflatoxin from the matrix during extraction (Schatzki and Toyofuku, 2003; Spanjer et al., 2006). However, our results showed no effect of blending time on the extraction efficiency and thus only support the assertion of swelling or an exchange of $\mathrm{H}$-bonding between aflatoxin and the matrix.

Besides improving recovery and precision of aflatoxin quantitation, slurry mixing procedure could reduce respiratory aflatoxin exposure of laboratory personnel associated with dry milling (Selim et al., 1998) and practically cut the cost associated with methanol usage by a factor of 4 (from $160 \mathrm{~mL}$ to $40 \mathrm{ml} / \mathrm{sample}$ as demonstrated in the present study). This is a great saving considering the high cost of purchasing of methanol and that wastes have to be discharged according to various national regulations for chemical waste disposal. However, the adoption of slurry mixing procedure is not without costs. Slurry making brings along extra personnel time involved in washing the blender or mixing equipment and increased volume of waste requiring proper discharge. While, it is important to perform economic analysis of adopting slurry mixing procedure as regards to waste management on a case-tocase basis, an analysis of adopting slurry mixing procedure by a laboratory in the Netherlands showed that slurringmixing had negligible additional costs (Spanjer et al., 2006). Innovatively, the slurry could be utilised as feed stocks for magic toxin detoxifying insects, such as Black Soldier Fly (BSF, Hermetia illucens) (Bosch et al., 2017) and produce high quality insect biomass for livestock feed (Wang and Shelomi, 2017). Moreover, the waste from the BSF is considered high quality fertiliser (Sheppard et al., 1994).

\section{Conclusions}

Sample preparation for mycotoxin quantification in maize meal, often overlooked among sampling plans and analytical methods, has been further studied by systematically comparing dry grind with slurry mixing procedure, for the determination of aflatoxin in maize samples. The current results provide evidence supporting the hypothesis that better recovery and better precision of aflatoxin quantification in maize meal is achievable by slurry mixing a large test portion and analysing a small fraction of it than using the conventional $50 \mathrm{~g}$ dry grind. Considering that globally aflatoxin regulatory limits for maize meant for human consumption are set mostly at level equal or less than $10 \mu \mathrm{g} / \mathrm{kg}$ where coefficient of variation test results are greatest, it is to the advantage of regulatory laboratories that use conventional laboratory mills to adopt slurring-mixing procedure to minimise the misclassification of lots, both accepting bad lots and rejecting good lots.

\section{Supplementary material}

Supplementary material can be found online at https://doi. org/10.3920/WMJ2018.2415.

Figure S1. Relationship between mass of slurry test-portion and filtrate volume.

Table S1. Error associated with scooping $25 \mathrm{~g}$ test portion from slurry prepared with different water/ maize meal ratios.

Table S2. Aflatoxin concentration and variance in ten samples as measured with $50 \mathrm{~g}$ dry grind, $12.5 \mathrm{~g}$ dry grind and $25 \mathrm{~g}$ slurry procedures plus analytical performance. 


\section{Acknowledgements}

The research was sponsored by the United States Department of Agriculture - Foreign Agriculture Service (USDA-FAS).

\section{Conflict of interest}

The authors have declared that there is no potential conflict of interest.

\section{References}

Bansal, J., Pantazopoulos, P., Tam, J., Cavlovic, P., Kwong, K., Turcotte, A.M., Lau, B.P.Y. and Scott, P.M., 2011. Surveys of rice sold in Canada for aflatoxins, ochratoxin A and fumonisins. Food Additives and Contaminants Part A 28: 767-774. DOI: https://doi.org/10.1080/ 19440049.2011.559279

Battilani, P., Toscano, P., Van der Fels-Klerx, H.J., Moretti, A., Camardo Leggieri, M., Brera, C., Rortais, A., Goumperis, T. and Robinson, T., 2016. Aflatoxin $B_{1}$ contamination in maize in Europe increases due to climate change. Scientific Reports 6: 24328. DOI: https:// doi.org/10.1038/srep24328

Berthiller, F., Brera, C., Iha, M.H., Krska, R., Lattanzio, V.M.T., MacDonald, S., Malone, R.J., Maragos, C., Solfrizzo, M., StranskaZachariasova, M., Stroka, J. and Tittlemier, S.A., 2017. Developments in mycotoxin analysis: an update for 2015-2016. World Mycotoxin Journal 10: 5-29. DOI: https://doi.org/10.3920/wmj2016.2138

Bosch, G., Van der Fels-Klerx, H.J., Rijk, T.C. and Oonincx, D.G., 2017. Aflatoxin $B_{1}$ tolerance and accumulation in black soldier fly larvae (Hermetia illucens) and yellow mealworms (Tenebrio molitor). Toxins 9: 185.

Cole, R.J. and Dorner, J.W., 1994. Extraction of aflatoxins from naturally contaminated peanuts with different solvents and solvent/peanut ratios. Journal of AOAC International 77: 1509-1511.

European Commission (EC), 2010. Commission regulation (EU) no 165/2010 of 26 February 2010, amending regulation (EC) no $1881 / 2006$ setting maximum levels for certain contaminants in foodstuffs as regards aflatoxin. Official Journal of the European Union L 50: 8-12.

Firdous, S., Ashfaq, A., Khan, S.J. and Khan, N., 2014. Aflatoxins in corn and rice sold in Lahore, Pakistan. Food Additives and Contaminants Part B 7: 95-98.

Food and Agriculture Organisation (FAO), 2003. Worldwide regulations for mycotoxins in food and feed in 2003. FAO, Rome, Italy.

Garrido, C.E., Pezzani, C.H. and Pacin, A., 2012. Mycotoxins occurrence in Argentina's maize (Zea mays L.), from 1999 to 2010. Food Control 25: 660-665.

Johansson, A.S., Whitaker, T.B., Giesbrecht, F.G., Hagler, W.M. and Young, J.H., 2000b. Testing shelled corn for aflatoxin, part II: modeling the observed distribution of aflatoxin test results. Journal of AOAC International 83: 1270-1278.

Johansson, A.S., Whitaker, T.B., Hagler, W.M., Giesbrecht, F.G., Young, J.H. and Bowman, D.T., 2000a. Testing shelled corn for aflatoxin, part I: estimation of variance components. Journal of AOAC International 83: 1264-1269.
Lewis, L., Onsongo, M., Njapau, H., Schurz-Rogers, H., Luber, G., Kieszak, S., Nyamongo, J., Backer, L., Dahiye, A., Misore, A., Rubin, C. and DeCock, K., 2005. Aflatoxin contamination of commercial maize products during an outbreak of acute aflatoxicosis in eastern and central Kenya. Environmental Health Perspectives 113: 1763. DOI: https://doi.org/10.1289/ehp.7998

Lippolis, V., Pascale, M., Valenzano, S. and Visconti, A., 2012. Comparison of slurry mixing and dry milling in laboratory sample preparation for determination of ochratoxin A and deoxynivalenol in wheat. Journal of AOAC International 95: 452-458.

Magamba, K., Matumba, L., Matita, G., Gama, A.P., Singano, L., Monjerezi, M. and Njoroge, S.M., 2017. Aflatoxin risk management in commercial groundnut products in Malawi (sub-Saharan Africa): a call for a more socially responsible industry. Journal of Consumer Protection and Food Safety 12: 309-316.

Manoza, F.S., Mushongi, A.A., Harvey, J., Wainaina, J., Wanjuki, I., Ngeno, R., Darnell, R., Gnonlonfin, B.G.J. and Massomo, S.M.S., 2017. Potential of using host plant resistance, nitrogen and phosphorus fertilizers for reduction of Aspergillus flavus colonization and aflatoxin accumulation in maize in Tanzania. Crop Protection 93: 98-105. DOI: https://doi.org/10.1016/j. cropro.2016.11.021

Matumba, L., Whitaker, T., Slate, A. and De Saeger, S., 2017. Current trends in sample size in mycotoxin in grains. Are we measuring accurately? Toxins 9: 276 (Abstract).

Nishimwe, K., Wanjuki, I., Karangwa, C., Darnell, R. and Harvey, J., 2017. An initial characterization of aflatoxin $B_{1}$ contamination of maize sold in the principal retail markets of Kigali, Rwanda. Food Control 73: 574-580.

Nowicki, T. and Roscoe, M., 2010. An alternative to slurry mixing to minimise sample preparation variance for determination of ochratoxin A in wheat. World Mycotoxin Journal 3: 147-156.

Ozer, H., Basegmez, H.O., Whitaker, T.B., Slate, A.B. and Giesbrecht, F.G., 2017. Sampling dried figs for aflatoxin - part 1: variability associated with sampling, sample preparation, and analysis. World Mycotoxin Journal 10: 31-40.

Schatzki, T.F. and Toyofuku, N., 2003. Sample preparation and presampling of pistachios. Journal of Agricultural and Food Chemistry 51: 6068-6072.

Schwartzbord, J.R. and Brown, D.L., 2015. Aflatoxin contamination in Haitian peanut products and maize and the safety of oil processed from contaminated peanuts. Food Control 56: 114-118.

Selim, M.I., Juchems, A.M. and Popendorf, W., 1998. Assessing airborne aflatoxin $B_{1}$ during on-farm grain handling activities. American Industrial Hygiene Association Journal 59: 252-256.

Shephard, G.S., 2016. Current status of mycotoxin analysis: a critical review. Journal of AOAC International 99: 842-848.

Sheppard, D.C., Newton, G.L., Thompson, S.A. and Savage, S., 1994. A value-added manure management system using the black soldier fly. Bioresource Technology 50: 275-279.

Spanjer, M.C., Scholten, J.M., Kastrup, S., Jörissen, U., Schatzki, T.F. and Toyofuku, N., 2006. Sample comminution for mycotoxin analysis: dry milling or slurry mixing? Food Additives and Contaminants 23: 73-83. 


\section{J. Kumphanda et al.}

Stroka, J., 2000. Determination of aflatoxins in food and feed with simple and optimised methods. Dissertation, Bergische UniversitätGesamthochschule, Wuppertal, Germany. Available at: http://elpub. bib.uni-wuppertal.de/edocs/dokumente/fb09/diss2000/stroka.

Turner, N.W., Bramhmbhatt, H., Szabo-Vezse, M., Poma, A., Coker, R. and Piletsky, S.A., 2015. Analytical methods for determination of mycotoxins: an update, 2009-2014. Analytica Chimica Acta 901: 12-33.

Velasco, J. and Morris, S.L., 1976. Use of water slurries in aflatoxin analysis. Journal of Agricultural and Food Chemistry 24: 86-88.

VICAM, 2014. Aflatest immuno-affinity procedure for popped popcorn. In: VICAM Fluorometer instruction manual. VICAM, Milford, MA, USA, p. 23.

Wang, Y.S. and Shelomi, M., 2017. Review of black soldier fly (Hermetia illucens) as animal feed and human food. Foods 6: 91.

Whitaker, T.B., 2003. Standardization of mycotoxin sampling procedures: an urgent necessity. Food Control 14: 233-237.

Whitaker, T.B., 2006. Sampling foods for mycotoxins. Food Additives and Contaminants 23: 50-61.

Whitaker, T.B. and Johansson, A.S., 2005. Sampling uncertainties for the detection of chemical agents in complex food matrices. Journal of Food Protection 68: 1306-1313.

Whitaker, T.B., Dickens, J.W. and Monroe, R.J., 1974. Variability of aflatoxin test results. Journal of the American Oil Chemists' Society 51: 214-218.
Whitaker, T.B., Dickens, J.W. and Monroe, R.J., 1980. A water slurry method of extracting aflatoxin from peanuts. Journal of the American Oil Chemists Society 57: 269-272.

Whitaker, T.B., Dowell, F.E., Hagler Jr., W.M., Giesbrecht, F.G. and Wu, J., 1994. Variability associated with sampling, sample preparation, and chemical testing for aflatoxin in farmers' stock peanuts. Journal of AOAC International 77: 107-116.

Whitaker, T.B., Hagler, W.M., Giesbrecht, F.G. and Johansson, A.S., 2000. Sampling, sample preparation, and analytical variability associated with testing wheat for deoxynivalenol. Journal of AOAC International 83: 1285-1292.

Whitaker, T., Horwitz, W., Albert, R. and Nesheim, S., 1996. Variability associated with analytical methods used to measure aflatoxin in agricultural commodities. Journal of AOAC International 79: 476485.

Whitaker, T.B., Slate, A.B., Doko, M.B., Maestroni, B.M. and Cannavan, A. (eds.), 2010. Sampling procedures to detect mycotoxins in agricultural commodities. Springer Science and Business Media, Berlin, Germany.

Williams, J.H., Phillips, T.D., Jolly, P.E., Stiles, J.K., Jolly, C.M. and Aggarwal, D., 2004. Human aflatoxicosis in developing countries: a review of toxicology, exposure, potential health consequences, and interventions. American Journal of Clinical Nutrition 80: 1106-1122. 